\title{
Deaths from necrotizing fasciitis in the United States, 2003-2013
}

\author{
N. ARIF, S. YOUSFI AND C. VINNARD* \\ Division of Infectious Diseases \& HIV Medicine, Department of Medicine, Drexel University College of \\ Medicine, Philadelphia, PA, USA
}

Received 28 September 2015; Final revision 19 October 2015; Accepted 20 October 2015; first published online 9 November 2015

\section{SUMMARY}

Necrotizing fasciitis (NF) is a life-threatening infection requiring urgent surgical and medical therapy. Our objective was to estimate the mortality burden of NF in the United States, and to identify time trends in the incidence rate of NF-related mortality. We obtained data from the National Center for Health Statistics, which receives information from death certificates from all states, including demographic information and cause of death. The U.S. Multiple Cause of Death Files were searched from 2003 to 2013 for a listing of NF (ICD-10 code M72.6) as either the underlying or contributing cause of death. We identified a total of 9871 NF-related deaths in the United States between 2003 and 2013, corresponding to a crude mortality rate of $4 \cdot 8$ deaths/ 1000000 person-years, without a significant time trend. Compared to white individuals, the incidence rate of NF-associated death was greater in black, Hispanic, and American Indian individuals, and lower in Asian individuals. Streptococcal infection was most commonly identified in cases where a pathogen was reported. Diabetes mellitus and obesity were more commonly observed in NF-related deaths compared to deaths due to other causes. Racial differences in the incidence of NF-related deaths merits further investigation.

Key words: Epidemiology, mortality, necrotizing fasciitis (NF), Staphylococcus, Streptococcus.

\section{INTRODUCTION}

Necrotizing fasciitis (NF) is a life-threatening infection requiring urgent surgical and medical therapy, and the suspected diagnosis must be quickly established by surgical exploration [1]. Development of NF may follow traumatic injury, surgical intervention, or may be spontaneous with a clear antecedent injury [2]. The rapid progression of infection hinges on the expression of bacterial toxins that permits the infection to spread rapidly along fascial planes, and

\footnotetext{
* Author for correspondence: Christopher Vinnard, MD, MPH, MSCE, Division of Infectious Diseases \& HIV Medicine, Drexel University College of Medicine, 245 N 15th Street, Philadelphia, PA 19102, USA.

(Email: christopher.vinnard@drexelmed.edu)
}

the appearance of the overlying skin often does not reflect the degree of destruction in deeper tissue layers [3]. Disruption of vascular flow rapidly leads to tissue necrosis, and the patient quickly develops an overwhelming sepsis syndrome which is fatal without tissue debridement and supportive care that includes effective antimicrobial therapy [4]. Although a clinical prediction rule was developed to guide decisionmaking [5], in subsequent work it was found to have limited sensitivity [6].

Cases of NF can been classified based on anatomical location and microbial aetiology. Bacterial pathogens that have been implicated in NF include group A Streptococcus (GAS), Staphylococcus aureus, Clostridium species, and mixed Gram-negative and anaerobic organisms [7]. Mixed infections with aerobic and anaerobic 
bacteria are classified as Type I, and mono-microbial infections with GAS or S. aureus are classified as Type II $\mathrm{NF}$ [8]. In a population-based study in the United States between 1996 and 2004, the incidence rate of invasive GAS infection was 3.5 cases $/ 100000$ person-years (p-yr), with $7 \cdot 2 \%$ of these cases presenting with NF [9].

There are little data available regarding time trends in the epidemiology of NF in the United States, despite concerns for an increasing burden of skin and soft tissue infections due to pathogens such as methicillinresistant $S$. aureus (MRSA) [10]. Our objective was to estimate the mortality burden of NF in the United States over a 10 -year period, and to identify temporal trends in the incidence of NF-related mortality during this period. In secondary analyses, we sought to characterize demographic factors and comorbid conditions associated with NF-related death during this period.

\section{METHODS}

\section{Setting}

Data were obtained from the National Center for Health Statistics, which receives information from death certificates from all 50 states, including demographic information and cause of death. The years 2003-2013 were included, given the change in cause-of-death codes from the International Classification of Diseases, 9th Revision (ICD-9) to the 10th revision (ICD-10) that occurred prior to 2003 [11]. The multiple cause of death (MCOD) data file includes both underlying and contributing causes (both diseases and injuries) that ultimately led to the individual's death.

\section{Case definition}

The U.S. Multiple Cause of Death Files were searched from 2003 to 2013 for a listing of necrotizing fasciitis (ICD10 code M72.6) as either the underlying or contributing cause of death. Analysis was not restricted to cases where NF was reported as the underlying cause of death, as the instructions for completing the death certificate refer to the underlying cause of death as 'the disease or injury which initiated the train of morbid events leading directly or indirectly to death or the circumstances of the accident or violence which produced the fatal injury' [12]. Thus, NF arising from an injury or surgical procedure may be recorded as a contributing cause of death, rather than the underlying cause of death. To explore the underlying microbiological diagnosis, each death record was examined for ICD-10 codes corresponding to streptococcal infection (ICD-10 codes A40.0, A40.1, A40.2, A40.3, A40.8, A40.9, A49.1, M00.0), staphylococcal infection (ICD-10 codes A41.0, A41.1, A41.2, A49.0, M00.2), gas gangrene (A48.0), Gram-negative organisms (A41.5), and anaerobes (A41.4).

\section{NF mortality rates adjusted for age, race/ethnicity, and sex}

Characteristics of individuals with NF-related deaths in the United States were summarized according to demographic characteristics. Age at death was defined based on the following age groups: $<1,1-4$, 5-14, 15-24, 25-34, 35-44, 45-54, 55-64, 65-74, 75$84, \geqslant 85$ years. Age-adjusted mortality rates and rate ratios (RRs) were calculated with 95\% confidence intervals (CIs) using bridged-race population estimates of U.S. census population data, which allows for comparison of different race categories across various collection systems [13]. Goodness-of-fit was examined by testing the statistical significance of the model deviance with the $\chi^{2}$ test, along with visual inspection of the plot of variance $v s$. mean.

\section{Time trend analysis}

Count data were modelled using maximum-likelihood analysis in a negative binomial regression model [14]. A negative binomial regression model was employed, rather than a Poisson model, because a violation of the assumption of equal mean and variance (overdispersion) was observed that reached statistical significance [15]. In order to test for a temporal trend in the rate of NF-associated deaths in the population, year was included as a dummy variable in the negative binomial regression model, with population as the offset.

\section{Matched case-control analysis for associated diagnoses}

To identify comorbid conditions associated with NF-related death, a previously validated approach developed by Redelings and colleagues [16] was employed. For each record of NF-related death during the study period, a random sample of deaths from the MCOD dataset during the same year was selected, and matched at a 10:1 ratio (controls:case) by age group, sex, and race/ethnicity. Groups of comorbidities were defined based on the leading ICD-10 diagnoses in all NF-related deaths. For each comorbidity, we calculated a matched odds ratio 


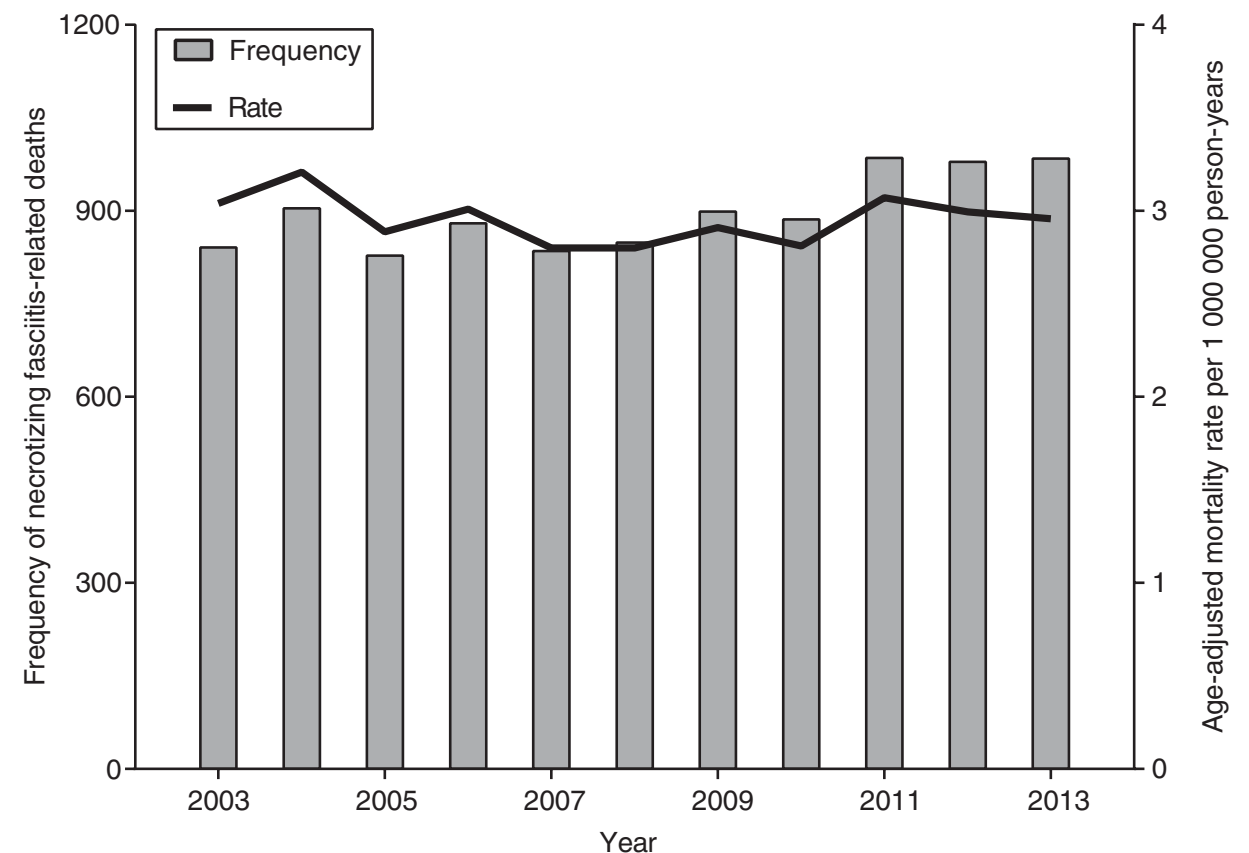

Fig. 1. Annual frequency and rate of necrotizing fasciitis-related deaths in the United States, 2003-2013.

Table 1. Necrotizing fasciitis-related mortality rates/1 000000 p-yr

\begin{tabular}{|c|c|c|c|}
\hline Characteristic & $\begin{array}{l}\text { Deaths } \\
n(\%)\end{array}$ & $\begin{array}{l}\text { Age-adjusted } \\
\text { mortality } \\
\text { rate/1 } 000000 \mathrm{p}-\mathrm{yr} \\
(95 \% \mathrm{CI})\end{array}$ & $\begin{array}{l}\text { Age-adjusted } \\
\text { mortality rate } \\
\text { ratios } \\
(95 \% \mathrm{CI})\end{array}$ \\
\hline \multicolumn{4}{|l|}{ Age group, $\mathrm{yr}^{*}(N=9870)$} \\
\hline$<1$ & $34(0 \cdot 3)$ & $0 \cdot 77(0 \cdot 51-1 \cdot 03)$ & $0 \cdot 45(0 \cdot 30-0 \cdot 61)$ \\
\hline $1-4$ & $5(0 \cdot 1)$ & $0.03(0 \cdot 00-0 \cdot 05)$ & $0 \cdot 02(0 \cdot 00-0 \cdot 03)$ \\
\hline $5-14$ & $34(0 \cdot 3)$ & $0 \cdot 08(0 \cdot 05-0 \cdot 10)$ & $0.04(0.03-0.06)$ \\
\hline $15-24$ & $73(0 \cdot 7)$ & $0 \cdot 15(0 \cdot 12-0 \cdot 19)$ & $0.09(0.07-0.11)$ \\
\hline $25-34$ & $297(3 \cdot 0)$ & $0.67(0.59-0.74)$ & $0.39(0.34-0.44)$ \\
\hline $35-44$ & $794(8 \cdot 0)$ & $1 \cdot 71(1 \cdot 59-1 \cdot 83)$ & Reference \\
\hline $45-54$ & $1876(19 \cdot 0)$ & $3 \cdot 91(3 \cdot 74-4 \cdot 09)$ & $2 \cdot 29(2 \cdot 10-2 \cdot 48)$ \\
\hline $55-64$ & $2461(24 \cdot 9)$ & $6 \cdot 56(6 \cdot 30-6 \cdot 81)$ & $3 \cdot 83(3 \cdot 52-4 \cdot 17)$ \\
\hline $65-74$ & $1893(19 \cdot 2)$ & $8 \cdot 22(7 \cdot 85-8 \cdot 59)$ & $4 \cdot 80(4 \cdot 41-5 \cdot 20)$ \\
\hline $75-84$ & $1585(16 \cdot 1)$ & $10 \cdot 99(10 \cdot 45-11 \cdot 53)$ & $6.42(5 \cdot 87-6.97)$ \\
\hline$\geqslant 85$ & $818(8 \cdot 3)$ & $14 \cdot 27(13 \cdot 29-15 \cdot 25)$ & $8 \cdot 34(7 \cdot 52-9 \cdot 15)$ \\
\hline \multicolumn{4}{|l|}{ Sex } \\
\hline Female & $4807(48 \cdot 7)$ & $2 \cdot 65(2 \cdot 57-2 \cdot 73)$ & Reference \\
\hline Male & $5063(51 \cdot 3)$ & $3 \cdot 31(3 \cdot 22-3 \cdot 39)$ & $1 \cdot 25(1 \cdot 20-1 \cdot 30)$ \\
\hline \multicolumn{4}{|l|}{ Race/ethnicity } \\
\hline White, non-Hispanic & $6548(66 \cdot 4)$ & $2 \cdot 58(2 \cdot 51-2 \cdot 65)$ & Reference \\
\hline Black, non-Hispanic & $1694(17 \cdot 2)$ & $5 \cdot 07(4 \cdot 88-5 \cdot 26)$ & $1.97(1.87-2 \cdot 06)$ \\
\hline Hispanic & $1209(12 \cdot 3)$ & $3 \cdot 67(3 \cdot 54-3 \cdot 80)$ & $1.42(1 \cdot 36-1 \cdot 49)$ \\
\hline Asian, non-Hispanic & $255(2 \cdot 6)$ & $1 \cdot 87(1 \cdot 68-2 \cdot 05)$ & $0.72(0.65-0.80)$ \\
\hline $\begin{array}{l}\text { American Indian or Alaskan } \\
\text { Native, non-Hispanic }\end{array}$ & $164(1 \cdot 7)$ & $7 \cdot 37(6 \cdot 46-8 \cdot 27)$ & $2 \cdot 86(2 \cdot 50-3 \cdot 21)$ \\
\hline
\end{tabular}

CI, Confidence interval.

* Age-specific mortality rates are reported 
(mOR) and the associated 95\% CI. All analyses were performed in Stata v. 13.0 (StataCorp., USA).

\section{RESULTS}

A total of 9871 NF-related deaths in the United States between 2003 and 2013 (Fig. 1) were identified, corresponding to a summary mortality rate of 4.8 deaths/ 1000000 p-yr. NF was reported as the underlying cause in $4185(42 \%)$ deaths, and a contributing cause of death in $5686(58 \%)$ deaths. An autopsy was reported in $885(9 \%)$ of 9871 deaths, and autopsy status was unknown in an additional 1034 (11\%) deaths. In a negative binomial regression model, there was not a significant time trend in the incidence rate of NF-associated deaths during the study period $(P=0 \cdot 47)$.

An underlying microbiological diagnosis was provided in $546(6 \%)$ of 9871 deaths. Of these 546 deaths, streptococcal infection was identified in $260(48 \%)$ deaths, staphylococcal infection in 119 (22\%) deaths, Gram-negative infection in 114 (21\%) deaths, gas gangrene in $28(5 \%)$ deaths, anaerobic infection in $15(3 \%)$ deaths, and a mixed infection was identified in $10(2 \%)$ deaths. Thus, type II (mono-microbial) NF due to either Staphylococcus or Streptococcus was identified in $379(69 \%)$ of 546 deaths where a microbiological diagnosis was included in the cause-of-death information.

Characteristics of individuals with NF-related death during this period are shown in Table 1. Advancing age was associated with an increasing rate of NF-related mortality, compared with a reference group of individuals aged 35-44 years, but no difference in mortality rates was observed in younger age groups. After adjusting for age, the rate of NF-related mortality in men was 1.25 times greater than the rate in women $(95 \%$ CI 1.20-1·30). The age-adjusted mortality rate in black individuals was nearly double the rate in white individuals $(1.97,95 \%$ CI $1.87-2.06)$, and the rate in Native Americans was nearly three times the rate in white individuals $(2 \cdot 86,95 \%$ CI $2 \cdot 50-3 \cdot 21)$. In contrast, NF-related mortality in Asian individuals was $28 \%$ lower than white individuals (age-adjusted mortality rate $0 \cdot 72,95 \%$ CI $0 \cdot 65-0 \cdot 80$ ).

We aggregated ICD-10 codes by block to describe the most common conditions included in the death certificates for NF-related deaths (Table 2). Diabetes mellitus was the most common comorbid condition, identified in $21 \%$ of all deaths. Renal disease, ischaemic heart disease, and substance use were also frequently reported as comorbid conditions. In a matched case-control study of comorbid conditions,
Table 2. Most common comorbid diagnoses in individuals with necrotizing fasciitis-related deaths in the United States, 2003-2013 ( $N=9817)$

\begin{tabular}{|c|c|c|}
\hline Comorbid condition & $\begin{array}{l}\text { ICD-10 } \\
\text { block codes }\end{array}$ & $\begin{array}{l}\text { Deaths } \\
n(\%)\end{array}$ \\
\hline Diabetes mellitus & E10-E14 & $2109(21)$ \\
\hline Other forms of heart disease & I30-I52 & $1972(20)$ \\
\hline Renal failure & N17-N19 & $1592(16)$ \\
\hline $\begin{array}{l}\text { Other diseases of the respiratory } \\
\text { system }\end{array}$ & J95-J99 & $1002(10)$ \\
\hline $\begin{array}{l}\text { Mental and behavioural } \\
\text { disorders due to psychoactive } \\
\text { substance use }\end{array}$ & F10-F19 & $934(10)$ \\
\hline Ischaemic heart diseases & $\mathrm{I} 20-\mathrm{I} 25$ & $753(8)$ \\
\hline Hypertensive diseases & I10-I15 & $717(7)$ \\
\hline Diseases of liver & K $70-$ K 77 & $617(6)$ \\
\hline $\begin{array}{l}\text { Obesity and other } \\
\text { hyperalimentation }\end{array}$ & E65-E68 & $519(5)$ \\
\hline $\begin{array}{l}\text { Chronic lower respiratory } \\
\text { diseases }\end{array}$ & J40-J47 & $338(3)$ \\
\hline Influenza and pneumonia & J09-J18 & $323(3)$ \\
\hline Metabolic disorders & E70-E90 & $304(3)$ \\
\hline $\begin{array}{l}\text { Malignant neoplasms of } \\
\text { digestive organs }\end{array}$ & $\mathrm{C} 15-\mathrm{C} 26$ & $294(3)$ \\
\hline $\begin{array}{l}\text { Malignant neoplasms, stated or } \\
\text { presumed to be primary, of } \\
\text { lymphoid, haematopoietic and } \\
\text { related tissue }\end{array}$ & $\mathrm{C} 81-\mathrm{C} 96$ & $282(3)$ \\
\hline
\end{tabular}

diabetes mellitus, renal failure, and obesity were significantly associated with NF-related death, compared with death due to other causes (Table 3). In contrast, heart disease and substance use were less commonly observed in NF-related deaths, compared to other causes.

\section{DISCUSSION}

In the United States from 2003 to 2013, the overall mortality rate for NF-related death was 4.8/1 000000 p-yr. Contrary to our hypothesis, there was not a significant time trend in the number of cases of fatal NF during the study period. Streptococcal infection was most commonly identified in cases where a pathogen was reported, although most cases did not have a microbiological diagnosis established in the death certificate.

There are limited prior data that estimate the disease burden of NF in the United States. In a study of medical claims records for cellulitis diagnoses, the incidence of NF in adults was estimated to be 40 cases $/ 1000000$ p-yr [17]. The incidence of NF in 
Table 3. Medical conditions associated with necrotizing fasciitis (NF) deaths in the United States, 2003-2013

\begin{tabular}{|c|c|c|c|c|}
\hline Condition & $\begin{array}{l}\text { ICD-10 } \\
\text { Codes }\end{array}$ & $\begin{array}{l}\text { NF-related deaths } \\
(N=9871) \\
n(\%)\end{array}$ & $\begin{array}{l}\text { Matched controls* } \\
(N=98710) \\
n(\%)\end{array}$ & $\begin{array}{l}\text { Matched OR } \\
(95 \% \mathrm{CI})\end{array}$ \\
\hline Diabetes mellitus & E10-E14 & $2109(21)$ & $10316(10)$ & $2 \cdot 37(2 \cdot 25-2 \cdot 50)$ \\
\hline Heart disease & I00-I99 & $3301(33)$ & $49007(50)$ & $0 \cdot 49(0 \cdot 47-0 \cdot 51)$ \\
\hline Renal failure & N17-N19 & 1695 (17) & $8223(8)$ & $2 \cdot 31(2 \cdot 18-2 \cdot 45)$ \\
\hline Substance use & F10-F19 & $934(9)$ & $12076(12)$ & $0 \cdot 74(0 \cdot 69-0 \cdot 80)$ \\
\hline Liver disease & K 70-K77 & $617(6)$ & $5872(6)$ & $1 \cdot 06(0 \cdot 97-1 \cdot 15)$ \\
\hline Obesity & E65-E68 & $519(5)$ & $1928(2)$ & $2 \cdot 83(2 \cdot 56-3 \cdot 13)$ \\
\hline
\end{tabular}

CI, Confidence interval.

* Each case of NF-related death was matched to 10 controls by age, sex, and race/ethnicity.

inpatient admissions in Texas varied between 59 cases/ 1000000 p-yr from 2001 to 2002 and 76 cases/1 000000 p-yr from 2009 to 2010, with an overall in-hospital mortality rate of $9 \cdot 3 \%[18]$. A larger study of necrotizing soft tissue infections using the Nationwide Inpatient Sample found that the number of hospital discharges for necrotizing soft tissue infections peaked in 2004, with an overall decline between 1998 and 2010 [19], although this approach may underestimate deaths that occur following discharge from the hospital [20]. Our estimate of 4.8 cases of fatal NF/ 1000000 p-yr is similar in scale to the population incidence rate that has recently been reported from New Zealand [21].

During the study period, we observed that fatal cases of NF were more common in older individuals, with the greatest number of cases observed in individuals aged 55-64 years. The association of advancing age with NF mortality increased for each age group beyond the reference group of 35- to 44-year-olds. In contrast with a previous report from Cook County, Illinois [22], we did not observe an increasing NF-associated mortality rate in individuals in the youngest age groups, and in fact observed declining mortality rates for every age group below the reference group.

In an adjusted analysis using population census data, we observed a greater incidence rate in black, Hispanic, and American Indian individuals compared to white individuals, and a lower incidence rate in Asian individuals. The observed relationship between race/ethnicity and NF-related mortality is likely multifactorial in aetiology. In a population-level study of sepsis syndrome in the United States, racial differences in outcomes were partly explained by differences in organ impairment [23]. The mortality rate was not adjusted for the presence of specific comorbidities, income level, or insurance status, which may further contribute to the observed mortality differences. Finally, disparities in access to healthcare, leading to delays in the recognition and appropriate management of NF, provide an additional explanation for the finding of increased mortality rates in Hispanic, black, and American Indian individuals compared to white individuals [24].

In a matched case-control study, comorbid conditions associated with NF-related deaths in the United States were identified, based on sampling of death certificate data from the entire population. Diabetes mellitus, obesity, and renal failure were significantly associated with NF-related death. In a hospital-based retrospective study of 299 patients with NF in New Zealand, diabetes and obesity were also found to be frequent comorbid conditions, identified in $32 \%$ and $23 \%$ of patients, respectively [25]. It is notable that a protective effect of diabetes mellitus in patients with NF has been reported previously in analyses of hospital discharge data [18, 26], which our approach was unable to address. Although outbreaks of NF have been reported in association with black-tar heroin use [27], there was no association between NF-related death and ICD-10 codes for substance use.

This study has several important limitations. Errors in the population estimates from the census data will be reflected in the calculated mortality rates. The completeness of a death certificate depends on the information available to the clinician at the time of death, and the appropriate recognition of all relevant contributing causes of death [28]. Additionally, relevant factors such as income level and health insurance status are not included on the death certificate, and there is limited information regarding the severity of comorbid factors such as diabetes mellitus, or the degree of organ failure. Strengths of the study include the 
completeness of death certificate reporting in the United States, and prior work with ICD coding to capture incident cases of NF in settings such as the National Surgical Quality Improvement Program [29].

In summary, we estimate the US mortality burden of NF to be $4 \cdot 8$ deaths $/ 1000000 \mathrm{p}$-yr, with a stable annual incidence rate during the period 2003-2013. Age, sex, and race were independently associated with the rate of NF-related deaths during the study period. The observed racial differences in the mortality rate of NF merits further investigation.

\section{ACKNOWLEDGEMENTS}

Dr Vinnard is supported by NIAID (K23AI102639-02).

\section{DECLARATION OF INTEREST}

None.

\section{REFERENCES}

1. Stevens DL, et al. Practice guidelines for the diagnosis and management of skin and soft tissue infections: 2014 update by the Infectious Diseases Society of America. Clinical Infectious Diseases 2014; 59: e10-52.

2. Hasham $\mathbf{S}$, et al. Necrotising fasciitis. British Medical Journal 2005; 330: 830.

3. Anaya DA, Dellinger EP. Necrotizing soft-tissue infection: diagnosis and management. Clinical Infectious Diseases 2007; 44: 705-710.

4. Anaya DA, et al. Predictors of mortality and limb loss in necrotizing soft tissue infections. Archives of Surgery 2005; 140: 151-157.

5. Wong CH, et al. The LRINEC (laboratory risk indicator for necrotizing fasciitis) score: a tool for distinguishing necrotizing fasciitis from other soft tissue infections. Critical Care Medicine 2004; 32: 1535-1541.

6. Wilson MP, Schneir AB. A case of necrotizing fasciitis with a LRINEC score of zero: clinical suspicion should trump scoring systems. Journal of Emergency Medicine 2013; 44: 928-931.

7. Brook I, Frazier EH. Clinical and microbiological features of necrotizing fasciitis. Journal of Clinical Microbiology 1995; 33: 2382.

8. Sarani B, et al. Necrotizing fasciitis: current concepts and review of the literature. Journal of the American College of Surgery 2009; 208: 279-288.

9. O'Loughlin RE, et al. The epidemiology of invasive group A streptococcal infection and potential vaccine implications: United States, 2000-2004. Clinical Infectious Disease 2007; 45: 853-862.

10. Miller LG, et al. Necrotizing fasciitis caused by community-associated methicillin-resistant Staphylococcus aureus in Los Angeles. New England Journal of Medicine 2005; 352: 1445-1453.
11. WHO. International Classification of Diseases, 10th Revision, 1992 (www.who.int/classifications/icd/en/).

12. WHO. Instruction for Classifying the Underlying Cause of Death, 2013. Hyattsville: National Center for Health Statistics, 2013 (www.cdc.gov/nchs/data/dvs/2a_2013. pdf).

13. CDC. National vital statistics system. United States bridged-race population estimates, 2010-NCHS (http://www.cdc.gov/nchs/nvss/bridged_race.htm).

14. Lloyd-Smith JO. Maximum likelihood estimation of the negative binomial dispersion parameter for highly overdispersed data, with applications to infectious diseases. PLoS ONE 2007; 2: e180.

15. Weaver CG, et al. Analyzing hospitalization data: potential limitations of Poisson regression. Nephrology Dialysis Transplantation 2015; 30: 1244-1249.

16. Redelings MD, Wise M, Sorvillo F. Using multiple cause-of-death data to investigate associations and causality between conditions listed on the death certificate. American Journal of Epidemiology 2007; 166: 104-108.

17. Simonsen SME, et al. Cellulitis incidence in a defined population. Epidemiology and Infection 2006; 134: 293-299.

18. Oud L, Watkins $\mathbf{P}$. Contemporary trends of the epidemiology, clinical characteristics, and resource utilization of necrotizing fasciitis in Texas: a population-based cohort study. Critical Care Research and Practice 2015. doi:10.1155/2015/618067.

19. Psoinos CM, et al. Contemporary trends in necrotizing soft tissue infections in the United States. Surgery 2013; 153: 819-827.

20. Hall WB, et al. The implications of long-term acute care hospital transfer practices for measures of in-hospital mortality and length of stay. American Journal of Respiratory and Critical Care Medicine 2012; 185: 53-57.

21. Das DK, Baker MG, Venugopal K. Increasing incidence of necrotizing fasciitis in New Zealand: a nationwide study over the period 1990 to 2006. Journal of Infection 2011; 63: 429-433.

22. Dworkin MS, et al. The epidemiology of necrotizing fasciitis including factors associated with death and amputation. Epidemiology and Infection 2009; 137: 1609-1614.

23. Mayr FB, et al. Infection rate and acute organ dysfunction risk as explanations for racial differences in severe sepsis. Journal of the American Medical Association 2010; 303: 2495-2503.

24. Soto GJ, Martin GS, Gong MN. Healthcare disparities in critical illness. Critical Care Medicine 2013; 41: 2784 2793.

25. Das DK, Baker MG, Venugopal K. Risk factors, microbiological findings and outcomes of necrotizing fasciitis in New Zealand: a retrospective chart review. $B M C$ Infectious Diseases 2012; 12: 348.

26. Mulla ZD, Gibbs SG, Aaronoff DM. Correlates of length of stay, cost of care, and mortality among patients hospitalized for necrotizing fasciitis. Epidemiology and Infection 2007; 135: 868-76.

27. Kimura AC, et al. Outbreak of necrotizing fasciitis due to Clostridium sordellii among black-tar heroin users. Clinical Infectious Diseases 2004; 38: e87. 
28. Messite J, Stellman SD. Accuracy of death certificate completion: the need for formalized physician training. Journal of the American Medical Association 1996; 275: 794-796.
29. Faraklas I, et al. Development and validation of a necrotizing soft-tissue infection mortality risk calculator using NSQIP Journal of the American College of Surgery 2013; 217: 153-160. 